\title{
Motivos de Sucesso, Afiliação e Poder: Evidência Confirmatória do Constructo
}

\author{
Arménio Rego e Teresa Carvalho \\ Universidade de Aveiro, Portugal
}

\begin{abstract}
RESUMO - O artigo expõe evidência confirmatória de validação do instrumento de medida dos motivos de sucesso, afiliação e poder proposto por Rego (2000). A amostra inclui 342 estudantes do ensino superior. Os dados sugerem o seguinte: a) o modelo tri-dimensional ajusta-se satisfatoriamente aos dados; b) os alphas são superiores a 0.70 ; c) tal como sugerido pela teoria, o motivo afiliativo relaciona-se negativamente com o desempenho dos estudantes; d) o motivo de sucesso explica o desempenho especialmente em condições de dificuldade intermédia; e) não se confirma a hipótese de o motivo de poder explicar o desempenho de estudantes com percepções de dificuldade elevada; f) os poderes explicativos dos motivos para o desempenho são baixos; g) o perfil motivacional traçado para a amostra converge com o descrito por pesquisas anteriores incidentes sobre populações portuguesas. Genericamente, a evidência empírica acalenta algum otimismo acerca das propriedades psicométricas do instrumento, mas estudos adicionais de validação são necessários.
\end{abstract}

Palavras-chave: motivos; sucesso; afiliação; poder; dificuldade percebida; desempenho dos estudantes universitários

\section{The Achievement, Affiliation and Power Motives: Confirmatory Validation}

\begin{abstract}
This paper aims at showing confirmatory empirical evidence to validate the instrument for measuring achievement, affiliation and power motives suggested by Rego (2000). Data from a sample comprising 342 students from higher education level was collected. The main findings are the following: a) the three-factor model suggested fits well the data; b) reliabilities are higher than $0.70 ;$ c) as suggested by theory, affiliation relates negatively with academic performance; d) achievement motive explains performance mainly when perceived difficulty is of intermediate level; e) the hypothesis proposing that power motive explains performance when difficulty is high does not confirm; f) in general, the predictive value of motives for performance is low; g) the motivational profile of the sample is similar to those of previous studies concerning Portuguese samples. In general, the evidence is optimistic about the psychometric properties of the instrument proposed by Rego, although further studies are necessary.
\end{abstract}

Key words: motives; achievement; affiliation; power; perceived difficulty; performance of higher education students

\section{A Caracterização dos Motivos}

Os motivos ocupam um lugar importante no elenco dos diversos elementos psicológicos que compõem a personalidade dos indivíduos (Winter, 1998). Podem ser definidos como as predisposições específicas interiorizadas pelas pessoas através do processo de socialização, as quais se organizam sob forma hierárquica (perfil, diversa de indivíduo para indivíduo) e imprimem uma determinada direcção ao comportamento (Reto, Lopes \& Cruz, 1989/90). Os motivos predominantes nos inúmeros trabalhos de McClelland e seus colaboradores são os de sucesso, afiliação e poder (tabela 1). Podem ser assim caracterizados (Koestner \& McClelland, 1992; McClelland, 1987; McClelland \& Koestner, 1992; Winter, 1998):

a) O motivo de sucesso representa uma orientação para a excelência, uma preferência por riscos moderados, a procura de feedback tendo em vista melhorar o desempenho. As pessoas fortemente motivadas para o sucesso

1 Endereço: Universidade de Aveiro, 3810-193 Aveiro (Portugal). Correio electrónico: arego@egi.ua.pt. tendem a ser "irrequietas" na sua atividade e a ser bem sucedidas como empreendedoras.

b) O motivo afiliativo representa uma orientação por relações quentes e amistosas. As pessoas vincadamente motivadas para a afiliação tendem a agir amigável e cooperativamente, embora possam atuar irada e defensivamente sob condições de ameaça.

c) O motivo de poder envolve uma orientação para o prestígio e a produção de impacto nos comportamentos ou emoções das outras pessoas. Uma elevada motivação para o poder está associada a atividades competitivas e assertivas, assim como ao interesse em alcançar e manter prestígio e reputação.

Sobre estes motivos têm sido desenvolvidas inúmeras pesquisas. Algumas abordam as suas origens e visam saber, por exemplo, em que medida os padrões educacionais estão associados a determinados perfis motivacionais (McClelland \& Pilon, 1983; McClelland, 1987). Outras procuram estudar os seus efeitos, abrangendo um largo leque de tópicos, de que se ilustram: o desempenho acadêmico dos estudantes (McClelland, 1972, 1987; Raynor, 1970; Rego, 1993, 1995, 1998a), os estilos preferenciais de gestão do conflito (Rego, 1995; Rego \& Jesuíno, 1999, 2001), a liderança organiza- 
Tabela 1. Caracterização sumária dos motivos de sucesso, afiliação e poder

\begin{tabular}{|c|c|}
\hline Motivos & O indivíduo: \\
\hline \multirow[t]{5}{*}{ Poder } & $\begin{array}{l}\text { - Procura controlar ou influenciar outras pessoas e dominar } \\
\text { os meios que lhe permitem exercer essa influência. }\end{array}$ \\
\hline & - Tenta assumir posições de liderança espontaneamente. \\
\hline & - Necessita/gosta de provocar impacto. \\
\hline & - Preocupa-se com o prestígio. \\
\hline & - Assume riscos elevados. \\
\hline \multirow[t]{7}{*}{ Sucesso } & $\begin{array}{l}\text { - Procura alcançar sucesso perante uma norma de } \\
\text { excelência pessoal. }\end{array}$ \\
\hline & - Aspira alcançar metas elevadas mas realistas. \\
\hline & - Responde positivamente à competição. \\
\hline & - Toma iniciativa. \\
\hline & $\begin{array}{l}\text { - Prefere tarefas de cujos resultados possa ser } \\
\text { pessoalmente responsável. }\end{array}$ \\
\hline & - Assume riscos moderados. \\
\hline & - Relaciona-se preferencialmente com peritos. \\
\hline \multirow[t]{4}{*}{ Afiliação } & - Procura relações interpessoais fortes. \\
\hline & $\begin{array}{l}\text { - Faz esforços para conquistar amizades e restaurar } \\
\text { relações. }\end{array}$ \\
\hline & - Atribui mais importância às pessoas do que às tarefas. \\
\hline & $\begin{array}{l}\text { - Procura aprovação dos outros para as suas opiniões e } \\
\text { atividades. }\end{array}$ \\
\hline
\end{tabular}

Construída a partir de: McClelland (1987), Koestner \& McClelland (1992), McClelland \& Koestner (1992), Veroff (1992b), Winter (1992b)

cional (McClelland \& Burnham, 1976; McClelland \& Boyatzis, 1982; Miller \& Toulouse, 1986; Rego, 1995, 1998b, 1999; Winter, 1991), a liderança política (Hernann, 1980; Winter, 1987; House, Spangler \& Woycke, 1991; Reto e cols., 1989/90; Schmitt \& Winter, 1998; Winter, 1998), o desenvolvimento econômico das nações (McClelland, 1961, 1976; Pereira, 1980), o empreendorismo e orientação empreendedora (Johnson, 1990; McClelland, 1961, 1965; Sagie \& Elizur, 1999) e o estado de saúde/doença dos indivíduos (Jemmott, 1987; McClelland, 1982, 1989; McClelland, Davidson \& Saron, 1985; Schultheiss, 1999).

\section{A Medição dos Motivos}

Uma das mais exuberantes controvérsias em torno dos motivos é a atinente aos métodos de medição. A preferência de McClelland sempre incidiu sobre uma técnica projectiva designada, por vezes, de Picture-Story Exercise (Koestner $\&$ McClelland, 1992). Trata-se de um "teste de apercepção temática" (TAT), desenvolvido originariamente por Murray (1938), que consiste numa série de figuras mostrando pessoas em situações ambíguas, perante cada uma das quais é solicitado às pessoas que inventem uma história. Presume-se que estes relatos inventivos revelam os sonhos, fantasias e aspirações dos sujeitos, tendo sido desenvolvidos sistemas de codificação que permitem analisar o conteúdo de cada história e pontuá-la nos três motivos (Heyns, Veroff \& Atkinson, 1958; McClelland, Atkinson, Clark \& Lowell, 1953; Veroff, 1992a; Winter, 1992a).
Existe, todavia, alguma polêmica acerca das vantagens desse método face aos questionários (Atkinson, 1982; Atkinson \& Birch, 1986; Fleming, 1982; McClelland, 1987; McClelland, Koestner \& Weinberger, 1989; Schmalt, 1999; Smith, 1992; Sokolowski, Schmalt, Langens \& Puca, 2000; Spangler, 1992; Weinberger \& McClelland, 1990; Weiner, 1989; Winter \& Stewart, 1977):

a) Os críticos do TAT alegam que ele é um método pouco fidedigno (seja do ponto de vista do teste-reteste ou da consistência interna) e detentor de reduzido poder preditivo dos comportamentos humanos. Advogam que os questionários demonstram adequada fidedignidade e maior valor preditivo.

b) Os paladinos do TAT concordam em que ele é um método muito sensível a influências situacionais. Mas alegam ser possível obter bons índices de fidedignidade se o teste for administrado corretamente. Aduzem, ainda, que a fidedignidade dos questionários tem sido exagerada. Advogam, também, que o poder preditivo do TAT é superior no que concerne aos comportamentos de longo prazo. Finalmente, esclarecem que, sendo inconscientes, os motivos não "devem" ser medidos através de escalas em que se convidam os indivíduos a auto-descreverem-se.

c) Alguns autores argumentam que os dois métodos são equivalentes. A plausibilidade desta tese é, todavia, seriamente posta em causa pelo fato de os dados disponíveis apontarem para a pequena ou nula correlação entre os motivos medidos pelas duas vias.

Uma posição distinta é que advoga que os motivos medidos pelas duas vias são conceitualmente diferentes. Mais especificamente, McClelland e seus colaboradores (Koestner \& McClelland, 1992; McClelland et al., 1989; McClelland \& Koestner, 1992; Mclelland, 1987; Weinberger \& McClelland, 1990) procedem à distinção entre os motivos implícitos (medidos pelo TAT) e os motivos explícitos ou auto-atribuídos (medidos pelos questionários). Os primeiros, sendo inconscientes, refletem-se nas fantasias descritas pelos indivíduos quando são colocados perante as figuras ambíguas do TAT. Os segundos, sendo conscientes, podem ser descritos pelos indivíduos quando questionados diretamente sobre as duas disposições motivacionais, objetivos e preferências em situações específicas. Aduzem os investigadores que os dois tipos de motivos denotam validade de construto em áreas diferentes (Schmalt, 1999; Sokolowski et al., 2000):

a) Os motivos implícitos explicam bem o que as pessoas realmente fazem, como despendem o seu tempo, e o seu comportamento operante a longo prazo (como a progressão na carreira profissional).

b) Os explícitos são bons preditores das atitudes, valores e objetivos conscientes, especialmente quando é requerido esforço.

Esta dicotomia foi alvo de escrutínio por parte de Schmalt (1976), que desenvolveu aquilo que se pode chamar a "terceira via": a técnica da grelha, a qual combina as características do TAT e dos questionários. Tal como no TAT, os indivíduos são colocados perante uma série de figuras ambíguas. 
Mas, em vez de serem convidados a descreverem (inventarem) histórias, são induzidos a responder a diversas questões para cada uma das figuras. Estas questões incorporam tendências motivacionais relacionadas com as emoções, cognições, antecipação de objetivos e ações instrumentais. Por exemplo, perante uma determinada figura, é solicitado aos inquiridos que refiram em que grau o indivíduo nela representado se sente bem, está ou não satisfeito com o que está a fazer, sente ou não que é capaz de realizar a tarefa. Os trabalhos empíricos que têm sido desenvolvidos (Schmalt, 1999; Schmalt \& Sokolowski, 2000; Sokolowski e cols., 2000) sugerem que o instrumento denota boas propriedades psicométricas.

\section{Objetivos}

O presente estudo insere-se no domínio psicométrico dos questionários. A grande vantagem destes reside no fato de serem um método mais prático, de mais fácil aplicação, mais rápido e mais barato. Consequientemente, têm sido desenvolvidas algumas medidas dessa natureza (Meharabian, 1969; Spence \& Helmreich, 1983; Stahl \& Harrell, 1982; Steers \& Braunstein, 1976). Um dos exemplos mais recentes foi protagonizado por Rego (1993, 1995, 1998a, 1998b, 1999, 2000; Rego \& Jesuino, 1999, 2001), ao adotar uma versão modificada e adaptada do questionário de medida das necessidades manifestas de Steers e Braunstein (1976). Os resultados de diversas pesquisas empíricas sugeriram que o instrumento denotava razoáveis propriedades psicométricas, em vários planos: a) consistência interna; b) relação com o TAT; c) poder preditivo dos estilos de gestão do conflito, dos impactos dos líderes sobre os seus subordinados e do desempenho acadêmico dos estudantes universitários. Um dos traços mais atrativos do questionário radica nas relações entre os motivos assim medidos e os medidos através do TAT (Rego, 1993):

a) Ambas as medidas denotaram relações idênticas entre os três motivos e o desempenho acadêmico de estudantes universitários.

b) Ambas traçaram idêntico perfil motivacional para uma amostra portuguesa (afiliação, sucesso e poder, por ordem decrescente). Esse perfil, no que respeita à posição dos motivos de poder e afiliativo, coincidia com os dados internacionais em que Portugal surge caracterizado como detentor de uma cotação afiliativa superior à cotação no motivo de poder (McClelland, 1975, 1987).

c) $\mathrm{O}$ fato de, nesse perfil, a cotação no motivo de sucesso ser mediana também é congruente com a idéia, empiricamente testada (Sagie, Elizur \& Yamauch, 1996) de que os indivíduos oriundos de culturas menos individualistas (Hofstede, 1997) - como é o caso de Portugal tendem a ser menos orientados para esse motivo. Acresce o fato de Portugal denotar uma cultura evitadora da incerteza (Hofstede, 1997), o que representa outra característica típica dos menos motivados para o sucesso.
Sucede que, nos seus primeiros estudos, Rego limitouse a medir cada motivo através de diversos descritores, confinando-se depois ao teste das consistências internas e ao estudo da validade externa. Não submeteu os dados a qualquer análise fatorial, deixando assim dúvidas sobre a validade da estrutura dimensional com que trabalhou. Acresce que alguns motivos (especialmente os de sucesso e poder) apresentaram recorrentemente inter-correlações cujos coeficientes importaria diminuir para efeitos de obtenção de ortogonalidade.

Com esse intuito, o investigador realizou pesquisa adicional (Rego, 2000). Construiu um questionário composto por 58 itens, recolhidos no instrumento anteriormente usado e em diversa literatura atinente a cada motivo. Os dados referentes a uma amostra de 243 indivíduos foram então submetidos a uma análise fatorial das componentes principais, tendo emergido uma estrutura tri-dimensional correspondente aos três motivos. As consistências internas revelaram-se satisfatórias (entre 0.73 e 0.83 ). E alguns dados apontaram elementos de validade externa. Por exemplo, o perfil da amostra coincidiu com os anteriormente obtidos, e revelouse bastante próximo do emergente de estudos internacionais relativos aos motivos de poder e afiliativo. A sub-amostra de gestores denotou cotação no motivo de poder significativamente superior à média, o inverso ocorrendo com o afiliativo. Esta evidência corrobora a idéia bem assente na literatura segundo a qual os indivíduos tendem a procurar atividades condizentes com os seus motivos. Compreende-se que os gestores "necessitem" do motivo de poder para exercerem influência sobre os outros, e denotem relativamente baixas necessidades afiliativas para poderem tomar decisões imparciais e mais "duras" quando necessário.

O presente estudo representa uma tentativa de validação adicional dos trabalhos de Rego (2000). O seu objetivo é duplo: a) confirmar a estrutura tri-dimensional do questionário; b) avançar com dados de validade externa, testando em que medida as relações entre os motivos e o desempenho acadêmico dos estudantes universitários são moderadas pelas dificuldades por eles percebidas. As pesquisas relacionadas com o motivo de sucesso têm produzido resultados pouco consistentes. Mas existe fundamento teórico para que tal aconteça (McClelland, 1987). Na verdade, é de esperar que a relação entre o motivo e o desempenho escolar seja positiva apenas quando os alunos perceberem que a dificuldade é moderada, receberem feedback da sua prestação e forem pessoalmente responsáveis pelos resultados (McClelland, 1987; McClelland \& Koestner, 1992; McKeachie, 1961; O' Conner, Atkinson \& Horner, 1966). Parafraseando McClelland (1987), esperar que assim não fosse seria o mesmo que propor que o drive da fome conduz ao melhor desempenho quando o incentivo comida não está presente (p. 227).

Na Universidade, o feedback da prestação está normalmente garantido, pois os alunos recebem as suas notas pelos testes realizados. A responsabilidade pessoal pelos resultados também constitui a situação mais comum, pois a grande 
maioria das avaliações baseia-se em testes individuais. Talvez por essas razões, Rego (1993, 1995, 1998a) tenha obtido coeficientes de correlação positivos entre este motivo e as classificações dos estudantes. O que não está adquirido, $a b$ initio, é o requisito respeitante ao desafio, pois as percepções sobre a dificuldade/desafio variam conforme o grau de dificuldade do próprio curso, as condições de cada turma, e as condições particulares de cada estudante. A pesquisa empírica realizada por Rego (1998a) sugere que, efetivamente, o motivo tende a explicar o desempenho especialmente em condições de dificuldade percebida. A primeira hipótese é, portanto, a seguinte: o motivo de sucesso relaciona-se positivamente com as classificações dos estudantes universitários, mas isso é especialmente notório quando estes percebem a sua vida acadêmica como moderadamente difícil.

Os mais motivados para o poder tendem a buscar reconhecimento e prestígio. Ora, o desempenho escolar pode constituir um modo através do qual os estudantes podem obtê-los (Costa \& McClelland, 1971, citado em McClelland, 1987). Todavia, nem todas as circunstâncias são propícias. Na verdade, sendo o incentivo inerente a este motivo a produção de impacto, é de crer que os alunos se esforcem mais e obtenham boas classificações, sobretudo em condições de dificuldade/desafio elevado, pois a probabilidade de produzirem impacto é maior (McClelland, 1987; McClelland \& Taegue, 1975; McClelland \& Watson, 1973; Rego, 2000; Winter, 1992b). Quando a dificuldade é diminuta ou moderada, o desafio é reduzido e o impacto produzido é pequeno. De acordo com o exposto, propomos a segunda hipótese: os estudantes mais motivados para o poder obtêm melhores classificações do que os restantes quando a dificuldade percebida é elevada.

Os mais afiliativos tendem a procurar relações pessoais fortes, esforçam-se por conquistar amizades, atribuem mais importância às pessoas do que às tarefas, procuram a aprovação social. Estas atividades são, em certa medida, incompatíveis com as longas horas de estudo e o isolamento que a vida de estudante, por vezes, exige. Existem, aliás, indicações de que o motivo se correlaciona positivamente com o número de horas de convívio com colegas (Stahl \& Harrell, 1982), levando a crer que os mais afiliativos têm menor predisposição para o estudo do que os restantes. Deve frisar-se que esta pressuposição não seja válida para o estudo/trabalho em grupo ou cooperativo (Klein \& Schnackenberg, 2000), caso em que os mais afiliativos poderão obter melhores desempenhos. Mas não parece razoável supor que a vida universitária portuguesa privilegia o trabalho cooperativo dos estudantes. Os testes de avaliação são individuais e, ao que nos é dado saber pela experiência, são escassas as avaliações assentes (quer exclusiva, quer predominantemente) em trabalhos de grupo. Sendo assim, é presumível que os mais afiliativos obtenham piores classificações do que os restantes. Isso foi, aliás, evidenciado por pesquisas anteriormente realizadas por Rego (1993, 1995, 2000).

O tópico assume, todavia, contornos ainda mais complexos, os quais importa debater. Por exemplo, existem indicações de que o motivo contribui para o bom desempenho quando está presente o incentivo afiliativo (McClelland, 1987). McKeachie (1961) constatou que os estudantes mais afiliativos trabalhavam mais e obtinham melhores performances do que os menos afiliativos em turmas em que o professor era considerado cordial e amistoso (interessando-se pessoalmente pelos alunos, chamando-os pelo seu próprio nome etc.).

A vida universitária apresenta, contudo, algumas particularidades. As turmas são relativamente grandes, o anonimato é mais forte, a relação professor-aluno é mais impessoal, e a probabilidade de o aluno receber apoio sócio-afetivo do professor é mais reduzida do que nos graus de ensino anteriores. Por outro lado, é mais reduzida a probabilidade de os alunos receberem (e valorizarem) o apoio, elogios e aprovação social dos Pais pela obtenção de boas classificações. Ou seja, o ambiente universitário tende a indisponibilizar o incentivo afiliativo, pelo que os alunos mais afiliativos têm poucas razões para se aplicarem com afinco na busca de boas classificações. Tendo em atenção o atrás exposto, propõe-se a seguinte hipótese: os mais motivados para a afiliação obtêm pior desempenho escolar do que os restantes.

\section{Método}

A amostra foi constituída por 342 estudantes da Universidade de Aveiro e da Escola Superior de Tecnologia e Gestão de Águeda, oriundos de 17 cursos (das áreas de Econonia, Gestão, Turismo, Comércio, Engenharias, Matemática, Design, Comunicação, Química). Cada aluno foi convidado a responder ao questionário de medida dos motivos, a um questionário de medida da dificuldade percebida, e a assinalar a sua média atual de curso (médias das classificações obtidas em todas as disciplinas feitas até ao momento).

O questionário relativo aos motivos continha os 27 emergentes da análise fatorial de Rego (2000), aos quais foram acrescentados três atinentes ao motivo de sucesso (ver anexo). Esta adição visou melhorar a consistência interna dos descritores atinentes a este motivo, que se situava abaixo de 0.70 em algumas sub-amostras inquiridas por Rego (2000). O questionário relativo à dificuldade percebida era composto por seis itens sugeridos por Rego (1998a), aos quais os estudantes foram convidados a responder através de escalas de diferencial semântico de sete pontos. Todos os questionários foram aplicados em sala de aula, após autorização dos docentes respectivos. Os dados relativos aos motivos foram submetidos a uma análise fatorial das componentes principais, tendo emergido uma estrutura fatorial muito similar à obtida por Rego (2000). As consistências internas variaram entre 0.72 e 0.82 . Foi, depois, executada uma análise fatorial confirmatória (método da máxima verosimilhança), tendo sido testado o modelo de três fatores. Os índices de ajustamento não se revelaram aceitáveis, o que não é surpreendente se atendermos ao elevado número de itens. Procedemos, então, à remoção de itens de acordo com os valores dos índices de modificação e dos resíduos estandardizados (Byrne, 1998; Joreskog \& Sorbom, 1993), tendo o questionário ficado reduzido a 18 itens. O modelo resultante 
Tabela 2. Motivos - análise fatorial confirmatória.

\begin{tabular}{|c|c|}
\hline Sucesso & $(0,79)$ \\
\hline $\begin{array}{l}\text { Gosto de aperfeiçoar constantemente as minhas } \\
\text { competências pessoais. }\end{array}$ & 0,58 \\
\hline Esforço-me por melhorar os meus resultados anteriores. & 0,71 \\
\hline $\begin{array}{l}\text { Gosto de saber se o meu trabalho foi ou não bem realizado, } \\
\text { de modo a fazer melhor no futuro. }\end{array}$ & 0,73 \\
\hline No trabalho, procuro fazer cada vez melhor. & 0,72 \\
\hline Tento fazer o meu trabalho de modo inovador. & 0,55 \\
\hline Afiliação & $(0,76)$ \\
\hline $\begin{array}{l}\text { Gosto de ser solidário com as outras pessoas, mesmo que } \\
\text { não sejam das minhas relações. }\end{array}$ & 0,56 \\
\hline $\begin{array}{l}\text { Sinto satisfação quando vejo que uma pessoa que me pediu } \\
\text { ajuda fica feliz com o meu apoio. }\end{array}$ & 0,52 \\
\hline $\begin{array}{l}\text { Se tivesse que despedir uma pessoa, procuraria sobretudo } \\
\text { compreender os seus sentimentos e apoiá-la no que me } \\
\text { fosse possível. }\end{array}$ & 0,51 \\
\hline No trabalho, gosto de ser uma pessoa amável. & 0,67 \\
\hline $\begin{array}{l}\text { Sinto-me satisfeito por trabalhar com pessoas que gostam de } \\
\text { mim. }\end{array}$ & 0,52 \\
\hline $\begin{array}{l}\text { No trabalho, presto muita atenção aos sentimentos dos } \\
\text { outros. }\end{array}$ & 0,57 \\
\hline $\begin{array}{l}\text { Fico preocupado quando sinto que, de alguma forma, } \\
\text { contribui para o mal-estar das relações no trabalho. }\end{array}$ & 0,60 \\
\hline Poder & $(0,71)$ \\
\hline Tenho um desejo secreto de chamar a atenção das pessoas. & 0,58 \\
\hline $\begin{array}{l}\text { Insisto numa determinada opinião apenas para "não dar o } \\
\text { braço a torcer". }\end{array}$ & 0,55 \\
\hline $\begin{array}{l}\text { Tenho discussões com os outros porque costumo insistir } \\
\text { naquilo que penso que deve ser feito. }\end{array}$ & 0,49 \\
\hline Procuro relacionar-me com pessoas influentes. & 0,57 \\
\hline $\begin{array}{l}\text { Se puder chamar pessoas para o trabalho da minha equipa, } \\
\text { procuro as que me permitam exercer mais influência. }\end{array}$ & 0,49 \\
\hline $\begin{array}{l}\text { Quando participo de algum convívio, aproveito para } \\
\text { influenciar os outros e obter o seu apoio para aquilo que } \\
\text { quero fazer. }\end{array}$ & 0,55 \\
\hline \multicolumn{2}{|l|}{ Índices de ajustamento } \\
\hline Qui-quadrado/Graus de liberdade & 1,9 \\
\hline Root mean square error of approximation & 0,052 \\
\hline Goodness of fit index & 0,92 \\
\hline Adjusted goodness of fit index & 0,90 \\
\hline Comparative fit index & 0,91 \\
\hline Incremental fit index & 0,91 \\
\hline Relative fit index & 0,80 \\
\hline
\end{tabular}

Entre parêntesis: alphas de Cronbach

Tabela 3. Dificuldade percebida - análise fatorial das componentes principais.

\begin{tabular}{lc}
\hline Itens & $\begin{array}{c}\text { Saturação } \\
\text { (loading) }\end{array}$ \\
\hline Em geral como considera o seu curso? & 0,90 \\
Que esforços tem despendido para fazer o seu curso? & 0,60 \\
Pensa que o seu curso é mais fácil ou mais difícil do que & 0,86 \\
os outros? & \\
Se lhe dissessem que o seu curso é difícil, concordaria? & 0,89 \\
Valor próprio & 2,69 \\
Variância explicada & $67,2 \%$ \\
Alpha de Cronbach & 0,83 \\
\hline
\end{tabular}

Tabela 4. Médias, desvios-padrão e correlações.

\begin{tabular}{lcccccc}
\hline & Média & DP & $\mathbf{1}$ & $\mathbf{2}$ & $\mathbf{3}$ & $\mathbf{4}$ \\
\hline 1. Sucesso & 5,8 & 0,7 & - & & & \\
2. Afiliação & 5,8 & 0,7 & $0,36^{* * *}$ & - & & \\
3. Poder & 3,5 & 0,8 & 0,03 & $-0,08$ & - & \\
4. Dific. percepcionada & 4,9 & 1,2 & $0,12^{*}$ & 0,07 & $-0,05$ & - \\
5. Média atual de curso & 12,1 & 1,2 & $0,13^{*}$ & $-0,06$ & $-0,04$ & 0,02 \\
\hline
\end{tabular}

${ }^{*} p<0.05 \quad * * * p<0.001$

Tabela 5. Regressões para o desempenho dos estudantes

\begin{tabular}{|c|c|c|c|}
\hline & \multirow[b]{2}{*}{$\begin{array}{l}\text { Amostra global } \\
\quad(n=342)\end{array}$} & \multicolumn{2}{|c|}{ Níveis de dificuldade percebida } \\
\hline & & $\begin{array}{c}\text { Média } \\
\text { (entre } 3 \text { e 5) } \\
(n=173)\end{array}$ & $\begin{array}{c}\text { Elevada } \\
(\text { superior a } 5) \\
(n=150)\end{array}$ \\
\hline Sucesso & $0,17 * *$ & $0,25 * *$ & 0,03 \\
\hline Afiliação & $-0,12 *$ & $-0,19^{*}$ & $-0,00$ \\
\hline Poder & $-0,05$ & $-0,02$ & $-0,04$ \\
\hline $\mathrm{F}$ & $3,19 *$ & $3,46^{*}$ & 0,10 \\
\hline $\mathrm{R}^{2}$ & $3 \%$ & $7 \%$ & $0 \%$ \\
\hline $\mathrm{R}^{2}$ ajustado & $2 \%$ & $5 \%$ & $0 \%$ \\
\hline
\end{tabular}

está exposto na tabela 2. Os índices de ajustamento são genericamente satisfatórios. Os lambdas são tendencialmente superiores a 0.50 . Os alphas ultrapassam sempre o mínimo de 0.70 sugerido por Nunnally (1978).

Para melhorar a consistência interna das escalas relativas à dificuldade percebida, foram removidos dois descritores. A fatorialização dos quatro itens remanescentes suscitou um único fator com valor próprio superior a 1, explicando $67.2 \%$ da variância (tabela 3 ). O alpha de Cronbach cifra-se em 0.83 .

\section{Resultados}

A tabela 4 expõe as médias, desvios-padrão e correlações. Os motivos de sucesso e afiliação correlacionam-se significativamente, embora o valor não pareça hipotecar a relativa independência das duas variáveis. $\mathrm{O}$ único motivo que se relaciona positiva e significativamente com o desempenho dos estudantes é o de sucesso.

A tabela 5 expõe os resultados das análises de regressão para o desempenho dos estudantes. Compara o poder explicativo atinente à amostra global com o poder preditivo relativo a duas sub-amostras que foram caracterizadas de acordo com os níveis de dificuldade percebida. Não foi considerado o nível de baixa dificuldade (cotação inferior a 3) por apenas conter 17 indivíduos. A evidência sugere que, globalmente, os mais motivados para o sucesso obtêm melhores desempenhos, ocorrendo o inverso com os mais afiliativos. O motivo de poder não denota qualquer poder explicativo. A variância explicada é bastante fraca. Quando se atenta na sub-amostra de estudantes com percepções de dificuldade média, o poder preditivo sofre um incremento, sendo que isso é mais evidente para o motivo de sucesso. $\mathrm{O}$ 
motivo afiliativo permanece com poder explicativo negativo. Contrariamente ao esperado, o motivo de poder não prediz o desempenho dos estudantes denotando maiores níveis de dificuldade percebida. Mesmo quando se operaram regressões para os alunos com cotação em dificuldade percebida superior a 6 e a 6.5 , o nulo poder explicativo permaneceu. Este padrão de resultados mantém-se quando se operam regressões para os diferentes tipos de cursos, consoante o nível de dificuldade média dos alunos que os freqüentam.

Embora tal não constasse dos objetivos do presente estudo, procedemos à análise do perfil motivacional da amostra, comparando-o com os perfis obtidos por Rego em estudos anteriores incidentes sobre populações portuguesas. O dado mais nítido reporta ao fato de o motivo de poder ser o menos vincado, o que reitera a evidência obtida invariavelmente nas pesquisas anteriores. A elevada motivação afiliativa também corrobora a evidência anterior. O motivo de sucesso emerge num patamar superior ao "habitual". Como elemento adicional de validação, sublinhe-se que os estudantes de Gestão denotam motivação para o poder significativamente superior à dos restantes (3.9 contra $3.5, p<0.01)$.

\section{Análise, Discussão e Conclusões}

O primeiro elemento digno de menção é o referente aos satisfatórios índices de ajustamento do modelo tri-fatorial aos dados. Os alphas de Cronbach são igualmente satisfatórios. Esta evidência corrobora a obtida previamente por Rego (2000), e sugere que o instrumento proposto denota propriedades psicométricas de assinalável valia.

O segundo dado mais relevante entronca nas hipóteses atinentes à relação entre os motivos e os desempenhos. Tal como previsto, o motivo afiliativo tende a relacionar-se negativamente com as classificações dos estudantes. É presumível que as características da vida universitária (anonimato, competição, avaliação individual, trabalho isolado) não disponibilizem o incentivo que induz os mais afiliativos a desenvolverem mais esforços e obterem níveis superiores de desempenho.

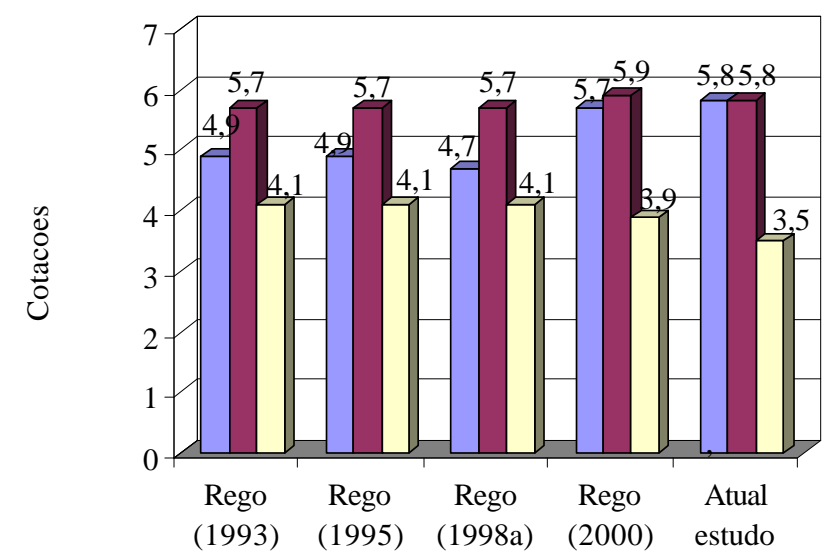

Figura 1. Comparação dos perfis motivacionais da amostra do presente estudo com os perfis de anteriores amostras
Globalmente, o motivo de sucesso tende a relacionar-se positivamente com o desempenho. Essa evidência compreende-se se atentarmos no fato de as características do ambiente acadêmico serem, à partida, propícias aos mais motivados para o sucesso. Designadamente, os estudantes recebem feedback do seu desempenho e são pessoalmente responsáveis pelos resultados obtidos. E parece razoável supor que existe, pelo menos, um nível de dificuldade intermédia na globalidade da vida universitária: as disciplinas vão variando ao longo do curso (assim colocando novos desafios), os alunos são submetidos a exames de avaliação e são impedidos de progredir se as classificações forem inferiores a um patamar mínimo (9.5, numa escala de 0 a 20, no sistema português).

Esta presunção projetada sobre a dificuldade percebida adquire verosimilhança empírica quando se atenta nos dados da presente pesquisa: dos 342 estudantes inquiridos, apenas $17(5 \%)$ expressaram percepções de baixa dificuldade (inferior a 3 pontos, na escala de 1 a 7); 173 (51\%) denotaram dificuldade intermédia (entre 3 e 5 pontos); e 150 (44\%) expressaram percepções de elevada dificuldade (superior a 5 pontos).

A nossa hipótese também aduzia, todavia, que o poder explicativo do motivo de sucesso para o desempenho seria superior em condições de dificuldade intermédia. Essa presunção confirma-se (tabela 5), sendo até que o poder preditivo é nulo em condições de dificuldade elevada. De qualquer modo, não deixa de ser saliente o fato de a variância explicada se cifrar em valores bastante baixos. Esta evidência concita algumas dúvidas sobre o papel que os motivos podem exercer na predição do desempenho acadêmico.

Esta dificuldade adquire dimensão mais notória quando se observa o fato empírico de que o motivo de poder não denota capacidade explicativa do desempenho, mesmo em condições de dificuldade elevada - assim não confirmando a nossa hipótese. Este dado é mesmo incongruente com o extraído por Rego (2000), induzindo a necessidade de se ponderarem vários aspectos metodológicos em pesquisas posteriores (tipos de curso estudados; instrumento de medida da dificuldade percebida). Ou seja: ao fato de os poderes explicativos serem tênues, acresce o caso de o motivo poder não explicar o desempenho nas condições teoricamente presumíveis. Há, por conseguinte, uma margem razoavelmente ampla de incerteza em torno da qualidade psicométrica do instrumento em causa.

De qualquer modo, importa registrar um elemento adicional que mitiga o cepticismo acabado de expor. É o que concerne ao perfil motivacional da amostra. Na verdade, no que diz respeito à posição dos motivos de poder e afiliativo, ele reitera aquilo que estudos anteriores de Rego sugeriram, estando de acordo com os dados internacionais nos quais Portugal surge caracterizado como detentor de uma cotação afiliativa superior à cotação no motivo de poder (McClelland, 1975, 1987). Relativamente ao motivo de sucesso, três interpretações plausíveis podem ser apontadas para o fato de a cotação deste estudo corresponder à afiliativa, sendo que a terceira permite acalentar algum otimismo psicométrico: A 
primeira interpretação sugere que a motivação para o sucesso dos portugueses (e, designadamente, dos estudantes) podem estar em incremento. Assim, teriam ocorrido alterações na sociedade e nos processos educacionais posteriores à Revolução democrática de 25 de Abril, que se fazem agora sentir quando os jovens ingressam na Universidade? A segunda interpretação refere-se a uma possibilidade de a amostra do presente estudo ter padecido de uma sobre-representação dos alunos de cursos de engenharias e da ausência de alunos de Humanidades. Se considerarmos os perfis detectados em estudos anteriores de Rego (1993, 1995), é possível que daí tenha derivado uma elevação da motivação para o sucesso da amostra. Estudos posteriores deverão aprofundar o estudo deste tópico, através nomeadamente da inclusão de estudantes de cursos das áreas de Humanidades (Letras, Filosofia, Sociologia, História, Educação de Infância). De qualquer modo, é digno de menção o fato de a amostra de Rego (2000) conter estudantes com essa proveniência, sem que daí tenha resultado abaixamento da cotação no motivo. Finalmente, uma terceira interpretação implica comparações com os estudos prévios de Rego, e permite atenuar algum cepticismo psicométrico anteriormente exposto. Os perfis das três primeiras amostras recolhidas por Rego foram medidos com uma versão mais "tosca" do instrumento só mais recentemente desenvolvido. Esse instrumento não fora sujeito a análises dimensionais, limitando-se Rego a calcular a consistência interna de escalas aprioristicamente imputadas a cada motivo. Quando Rego (2000) aprimorou as características psicométricas da medida, a cotação no motivo de sucesso sofreu um incremento, aproximando-se da pontuação no motivo afiliativo. O presente estudo, ao recorrer ao mesmo instrumento de Rego (2000) - ainda que com pequenos elementos adicionais de validação - reitera precisamente essa mesma tendência.

Importa sublinhar que este perfil (que coloca as motivações para o sucesso e afiliação no mesmo patamar) é bastante semelhante a outro que Rego (1993) obteve com o TAT. Aí, os dois motivos situavam-se precisamente em planos muito similares, quer para a amostra global quer para diversas sub-amostras. Dado que, nessa pesquisa, também o motivo de poder emergia em último lugar, fica patente a similitude entre o perfil desenhado pelo TAT e aquele que o "novo" instrumento de Rego (submetido a validação adicional na presente pesquisa) produz.

Há, por conseguinte, algumas razões para presumir que esta nova medida sugerida por Rego concita dados de validação equiparáveis aos gerados pelo TAT. De qualquer maneira, afirmações mais peremptórias só poderão ser enunciadas quando se cotejarem, em iguais amostras, dados de validação fornecidos pelo TAT e por este "novo" instrumento de Rego.

Eis, agora, a necessidade de referir algumas limitações da pesquisa. Em primeiro lugar, os dados foram obtidos em duas instituições apenas. Estudos posteriores deverão alargar o âmbito amostral a outras instituições universitárias e politécnicas. Em segundo lugar, é excessivamente redutor aquilatar a validade externa do construto recorrendo funda- mentalmente ao desempenho dos estudantes. Pesquisas vindouras deverão testar a validade através do recurso a outras variáveis dependentes (p. ex., eficácia dos líderes, propensão empreendedora, estilos preferenciais de gestão do conflito). Em terceiro lugar, é possível que a medida usada para mensurar a dificuldade percebida não englobe os aspectos mais relevantes para a verdadeira dificuldade sentida pelos estudantes. Quiçá seja essa uma das principais razões pelas quais algumas relações moderadas lançadas nas hipóteses não se tenham confirmado. Finalmente, importaria comparar a evidência empírica fornecida pelo instrumento aqui proposto com a facultada por um TAT. Esta constitui, indubitavelmente, uma tarefa de enorme valia para satisfazer os intuitos de validação subjacentes à presente investigação.

Em suma, a evidência empírica exibida reforça alguns elementos de validação do instrumento proposto por Rego (2000). Todavia, novas investigações são necessárias para que se torne mais clara a medida em que ele pode ser um substituto válido do TAT e/ou da técnica da grelha.

\section{Referências}

Atkinson, J.W. \& Birch, D. (1986). Fundamentals of the dynamics of action. Em Julius Kull \& J.W.Atkinson (Orgs.), Motivation, thought, and action (pp.16-48). New York: Praeger Publishers.

Atkinson, J.W. (1982). Motivation determinants of thematic apperception. Em A. Stewart (Org.), Motivation and Society (pp. 3-40). San Francisco: Jossey-Bass Inc., Publishers.

Byrne, B.M. (1998). Structural Equation Modeling with Lisrel, Prelis, and Simplis. London: Lawrence Erlbaum.

Fleming, J. (1982). Projective and psychometric approaches to measurement - the case of fear of sucess. Em Abigail J. Stewart (Org.), Motivation and Society - A Volume in Honor of David McClelland (pp. 63-96). S. Francisco: Jossey-Bass Publishers.

Hernann, M.G. (1980). Assessing the personalities of soviet politburo members. Personality and Social Psychology Bulletin, 6(3), 332-352.

Heyns, R.W., Veroff, J. \& Atkinson, J.W. (1958). A scoring manual for the affiliation motive. Em J.W. Atkinson (Org.), Motives in fantasy, action and society (pp. 205-218). Princeton, NJ: Van Nostrand.

Hofstede, G. (1997). Culturas e organizações - compreender a nossa programação mental. Lisboa: Edições Sílabo.

House, R., Spangler, W.D. \& Woycke, (1991). Personality and charisma in the US presidency: A psychological theory of leader effectiveness. Administrative Science Quarterly, 36, 364-396.

Jemmott, J.B. (1987). Social motives and susceptibility to disease: Stalking individual differences in health risks. Journal of Personality, 55, 267-298.

Joreskog, K. \& Sorbom, D. (1993). Lisrel 8: Structural Equation Modeling with the Simplis Command Language. Scientific Software International.

Johnson, B.R. (1990). Toward a multidimensional model of entrepreneeurship: the case of achievement motivation and the entrepreneur. Entrepreneurship Theory \& Practice, Spring, 39-54. 
Klein, J.D. \& Schnackenberg, H.L. (2000). Effects of informal cooperative learning and the affiliation motive on achievement, attitude, and student interactions. Contemporary Educational Psychology, 25, 332-341.

Koestner, R. \& McClelland, D.C. (1992). The affiliation motive. Em C.P. Smith (Org.), Motivation and Personality: Handbook of Thematic Content Analysis (pp.205-210). Cambridge: Cambridge University Press.

McClelland, D.C. \& Boyatzis, R. E. (1982). The leadership motive pattern and long term success in management. Journal of Applied Psychology, 67(6), 737-743.

McKeachie, W.J. (1961). Motivation, teaching methods, and college learning. Em M. R. Jones (Ed.), Nebraska Symposium on Motivation. Lincoln: University of Nebraska Press.

McClelland, D.C. \& Burnham, D.H. (1976). Power is the great motivator. Harvard Business Review, March-April, 100-110.

McClelland, D.C. \& Koestner, R. (1992). The achievement motive. Em Charles P. Smith (Org.), Motivation and Personality: Handbook of Thematic Content Analysis (pp.143-152). Cambridge: Cambridge University Press.

McClelland, D.C. \& Pilon, D.A. (1983). Sources of adult motives in patterns of parent behavior in early childhood. Journal of Personality and Social Psychology, 44 (3), 564-574.

McClelland, D.C. (1961/1976). The achieving society. Princeton, N. J: Van Nostrand.

McClelland, D.C. (1962). Business drives and national achievement. Harvard Business Review, July-August,103-105.

McClelland, D.C. (1965). Achievement and entrepreneurship: A longitudinal study. Journal of Personality and Social Psychology, 1, 389-392.

McClelland, D.C. (1972). What is the effect of achievement motivation training in the schools? Teachers College Record, 74, 129-145.

McClelland, D.C. (1982). The need for power, sympathetic activation and illness. Motivation and Emotion, 6(1), 31-41.

McClelland, D.C. (1987). Human Motivation. Cambridge: Cambridge University Press.

McClelland, D.C. (1989). Motivational fators in health and disease. American Psychologist, 44, 675-683.

McClelland, D.C., Atkinson, J. W., Clark, R.A., \& Lowell, E.L. (1953). The Achievement Motive (pp. 107-138). New York: Appleton-Century-Crofts.

McClelland, D.C., Davidson, R.J. \& Saron, C. (1985). Stressed power motivation, sympathetic activation, immune function and illness. Advances, 2, 42-52.

McClelland, D.C. \& Taegue, G. (1975). Predicting risk preferences among power-related tasks. Journal of Personality, 43, 266285.

McClelland, D.C. \& Watson, R.I. (1973). Power motivation and risk-taking behavior. Journal of Personality, 41, 121-139.

McClelland, D.C., Koestner, R., \& Weinberger, J. (1989). How do self-attributed and implicit motives differ? Psychological Review, 96, 690-702.

McClelland, D.C. (1975). Power: The Inner Experience. New York: Irvington Publishers.

Mehrabian, A. (1969). Measures of Achieving Tendency. Educational and Psychological Measurement, 29, 445-451.
Miller, D. \& Toulouse, J. (1986). Chief executive personality and corporate strategy and structure in small firms. Management Science, 32(11), 1389-1409.

Murray, H.A. (1938). Explorations in personality. New York: Oxford University Press.

Nunnally, J.C. (1978). Psychometric theory (2 ${ }^{\text {nd }}$ ed.). New York: McGraw-Hill.

O‘Conner, P.A., Atkinson, J. W., \& Horner, M. (1966). Motivational Implications of Ability Grouping in Schools. Em J. W. Atkinson \& N.T. Feather (Orgs.), A Theory of Achievement Motivation. New York: Wiley.

Pereira, O.G. (1980). Psicologia económica: disciplina do futuro. Universidade Nova de Lisboa, Faculdade de Economia.

Raynor, J.O. (1970). Relationships between achievement.related motives, future orientation, and academic performance. Journal of Personality and Social Psychology, 15(1), 28-33.

Rego, A. \& Jesuino, J.C. (1999). Motives and conflict management styles. Trabalho apresentado em $9^{\text {th }}$ European Congress on Work and Organizational Psychology, 12-15 May, EspooHelsinki, Finland.

Rego, A. \& Jesuino, J.C. (2001). Estilos de gestão do conflito e padrões motivacionais. Aceite para publicação na revista Comportamento Organizacional e Gestão.

Rego, A. (1993). Níveis de motivação e graus de desempenho. Revista Portuguesa de Gestão, II, 69-82.

Rego, A. (1995). O Modelo Motivacional de McClelland - uma aplicação. Dissertação de Mestrado, ISCTE, Lisboa.

Rego, A. (1998a). Motivações e desempenho de estudantes universitários. Análise Psicológica, 4, 635-646.

Rego, A. (1998b). Configurações motivacionais dos gestores e respectivos impactes nos subordinados. Revista Portuguesa de Gestão, I, 53-65.

Rego, A. (1999). Motivational configurations of managers and their impact on subordinates. Trabalho apresentado em Annual Convention of the International Council of Psychologists, Salem. Massachusetts, USA, August 15-18.

Rego, A. (2000). Os motivos de sucesso, afiliação e poder desenvolvimento e validação de um instrumento de medida. Análise Psicológica, 3(XVIII), 335-344.

Reto, L. \& Lopes, A. (1989/1990). Liderança política-personalidades, conjuntura e representações. Revista de Gestão, ISCTE, VII, 13-17.

Sagie, A. \& Elizur, D. (1999). Achievement motive and entrepreneurial orientation: a structural analysis. Journal of Organizational Behavior, 20, 375-387.

Sagie, A., Elizur, D. \& Yamauchi, H. (1996). The structure and strengh of achievement motivation: a cross-cultural comparison. Journal of Organizational Behavior, 17, 431-444.

Schmalt, H. \& Sokolowski, K. (2000). Zum gegenwärtigen stand der motivdiagnostik (The current status of motive measurement). Diagnostica, 46(3), 115-123.

Schmalt, H. D. (1976). Die Messung des Leistungsmotivs [The measurement of the achievement motive]. Göttingen, Germany: Hogrefe.

Schmalt, H. (1999). Assessing the achievement motive using the grid technique. Journal of Research in Personality, 33, 109130 . 
Schmitt, D.P. \& Winter, D.G. (1998). Measuring the motives of soviet leadership and soviet society: congruence reflected or congruence created? Leadership Quarterly, 9(3), 293-307.

Schultheiss, O.C. (1999). Psychological and health correlates of implicit motives. Trabalho apresentado em $107^{\text {th }}$ Annual Convention of the American Psychological Association, Boston, Massachusetts, August 20-24.

Smith, C.P. (1992). Reliability issues. Em C.P. Smith (Org.), Motivation and Personality: Handbook of Thematic Content Analysis (pp. 126-139). Cambridge: Cambridge University Press.

Sokolowski, K., Schmalt, H., Langens, T.A. \& Puca, R.M. (2000). Assessing achievement, affiliation, and power motives all at once: the multi-motive grid (MMG). Journal of Personality Assessment, 74(1), 126-145.

Spangler, W.D. (1992). Validity of questionnaire and TAT measures of need for achievement: two meta-analyses. Psychological Bulletin, 112(1), 140-154.

Spence, J.T. \& Helmreich, R.L. (1983). Achievement-related motives and behaviors. In J. T. Spence (Ed.), Achievement and achievement motives: Psychological and sociological approaches (pp. 9-74). San Francisco: W. H. Freeman.

Stahl, M.J. \& Harrell, A.M. (1982). Evolution and validation of a behavioral decision theory measurement approach to achievement, power, and affiliation. Journal of Applied Psychology, 67 (6), 744-751.

Steers, R.M. \& Braunstein, D.N. (1976). A behaviorally-based measure of manifest needs in working settings. Journal of Vocational Behavior, 9, 251-266.

Veroff, J. (1992a). A scoring manual for the power motive. In J.W. Atkinson (Ed.), Motives in fantasy, action and society (pp. 219233). Princeton, NJ: Van Nostrand.

Veroff, J. (1992b). Power motivation. In C.P. Smith (Ed.), Motivation and Personality: Handbook of Thematic Content Analysis (pp. 278-285). Cambridge: Cambridge University Press.
Weinberger, J. \& McClelland, D.C. (1990). Cognitive versus traditional motivational models - irreconcilable or complementary?. Em E. T. Higgins \& R. M. Torrentino (Orgs.), Handbook of Motivation and Cognition - Fondations of Social Behavior (volume 2; pp. 562-597). New York: The Guilford Press.

Weiner, B. (1989). Human Motivation. Hillsdale, New Jersey: Lawrence Erlbaum Associates, Publishers.

Winter, D.G. (1987). Leader appeal, leader performance, and the motive profiles of leaders and behaviors: A study of american presidents and elections. Journal of Personality and Social Psychology, 52(1), 196-202.

Winter, D.G. (1991). A motivational model of leadership: Predicting long-term management success from TAT measures of power motivation and responsibility. Leadership Quarterly, 2, 67-80.

Winter, D.G. (1998). A motivational analysis of the Clinton first term and the 1996 presidencial campaign. Leadership Quarterly, 9(3), 367-376.

Winter, D.G. (1992a). A revised scoring system for the power motive. Em C. P. Smith (Org.), Motivation and Personality: Handbook of Thematic Content Analysis (pp. 311- 324). Cambridge: Cambridge University Press.

Winter, D.G. (1992b). Power motivation revisited. Em C. P. Smith (Org.), Motivation and Personality: Handbook of Thematic Content Analysis (pp. 301-310). Cambridge: Cambridge University Press.

Winter, D.G. \& Stewart, A. (1977). Content analysis as a technique for assessing political leaders. Em M. G. Hernann (Org.), A psychological examination of political leaders (pp. 27-61). New York: Free Press. 


\section{A. Rego e T. Carvalho}

\section{Anexo}

Itens emergentes da análise fatorial das componentes principais executada por Rego (2000).

Sinto-me satisfeito quando tenho relações amistosas com a maior parte das outras pessoas. (Af)

Quando chego a algum lugar, fico satisfeito se as pessoas me prestam atenção. (Po)

Se me derem a escolher, gosto de optar por tarefas de cujos resultados eu possa ser responsabilizado. (Su)

No trabalho, gosto de ter amigos com quem possa partilhar as minhas alegrias e tristezas. (Af)

Tenho um desejo secreto de chamar a atenção das pessoas. (Po)

Sinto-me atraído por tarefas novas. (Su)

Procuro saber se os meus pontos de vista prejudicam o bem-estar das outras pessoas. (Af)

Sinto prazer quando consigo convencer os meus adversários a aceitarem as minhas posições. (Po)

Se sinto dificuldades numa tarefa que me foi atribuída, procuro a ajuda dos especialistas no assunto. ( $\mathrm{Su}$ )

Gosto de ser solidário com as outras pessoas, mesmo que não sejam das minhas relações. (Af)

Insisto numa determinada opinião apenas para "não dar o braço a torcer". (Po)

Gosto de aperfeiçoar constantemente as minhas competências pessoais. ( $\mathrm{Su}$ )

Sinto satisfação quando vejo que uma pessoa que me pediu ajuda fica feliz com o meu apoio. (Af)

Tenho discussões com os outros porque costumo insistir naquilo que penso que deve ser feito. (Po)

Esforço-me por melhorar os meus resultados anteriores. (Su)

Gosto de fazer amizades que se mantenham para além das relações de trabalho. (Af)

Procuro relacionar-me com pessoas influentes. (Po)

Se tivesse que despedir uma pessoa, procuraria sobretudo compreender os seus sentimentos e apoiá-la no que me fosse possível. (Af)

Procuro evitar que me atribuam maiores responsabilidades. (Su)

No trabalho, gosto de ser uma pessoa amável. (Af)

Se puder chamar pessoas para o trabalho da minha equipa, procuro as que me permitam exercer mais influência. (Po)

Sinto-me satisfeito por trabalhar com pessoas que gostam de mim. (Af)

Quando as dificuldades são grandes, tenho tendência para desistir de procurar o que pretendia. (Su)

No trabalho, presto muita atenção aos sentimentos dos outros. (Af)

Gosto de saber se o meu trabalho foi ou não bem realizado, de modo a fazer melhor no futuro*. (Su)

Fico preocupado quando sinto que, de alguma forma, contribui para o mal-estar nas relações de trabalho. (Af)

No trabalho, procuro fazer cada vez melhor*. (Su)

Quando participo de algum convívio, aproveito para influenciar os outros e obter o seu apoio para aquilo que quero fazer. (Po)

Tento fazer o meu trabalho de modo inovador*. (Su)

* Acrescentados para melhorar a consistência interna das escalas atinentes ao motivo de sucesso. Su: sucesso; Af: afiliação; Po: poder 